\title{
Penerapan model pembelajaran OIDDE untuk meningkatkan keterampilan pembelajaran berbasis karakter pada guru pendidikan dasar dan menengah
}

\author{
Atok Miftachul Hudha ${ }^{1 *}$, Sukarsono ${ }^{2}$, Ning Rahayu Handayani ${ }^{3}$ \\ 1 Universitas Muhammadiyah Malang, Indonesia, email: atok1964@gmail.com \\ 2Universitas Muhammadiyah Malang, Indonesia, email: sukarsono_umm@yahoo.com \\ 3 Universitas Muhammadiyah Malang, Indonesia, email: ningrahayu930@gmail.com \\ *Koresponden penulis
}

\section{Info Artikel}

Diajukan: 01 Jan 2021

Diterima: 19 Jun 2021

Diterbitkan: 27 Jun 2021

Keywords:

character; education;

learning model; oidde

Kata Kunci:

karakter; model

pembelajaran; oidde;

pendidikan

\section{Lisensi:}

cc-by-sa

\begin{abstract}
The application of character values through classroom learning has not been maximal because teachers have difficulty choosing the right learning model. The OIDDE (Orientation, Identify, Discussion, Decision, and Engage in Behavior) learning model is appropriate to implement. This article aims to describe the implementation of teacher assistance activities in developing character values through learning by applying the OIDDE learning model. The subjects of the service were 12 teachers at SD / MI levels, 12 teachers from SMP / MTs, and 15 teachers at SMA / SMK / MA levels from 39 schools in Batu City, East Java. The activity was carried out for 6 months using the Forum Group Discussion (FGD) method, workshops, hands-on practice, outreach, and evaluation. The evaluation of community service is carried out thoroughly, from the process to the output, especially the seriousness of the teacher in participating in the activities to the skills in applying the model. The results of the process evaluation show that, the service activity is carried out well, the average attendance is $85 \%$, and as many as $100 \%$ of the teachers become the Master Teacher model. OIDDE learning, and has the right to provide tutors with OIDDE learning models.
\end{abstract}

\section{Abstrak}

Penerapan nilai-nilai karakter melalui pembelajaran di kelas belum maksimal karena guru kesulitan memilih model pembelajaran yang tepat. Model pembelajaran OIDDE (Orientation, Identify, Discussion, Decision, and Engage in Behavior) tepat untuk diimplementasikan. Artikel ini bertujuan mendeskripsikan pelaksanaan kegiatan pendampingan guru dalam pengembangan nilai karakter melalu pembelajaran dengan model pembelajaran OIDDE. Metode pengabdian dilakukan melalui kerjasama kemitraan, workshop, dan pelatihan dengan subjek pengabdian 12 guru jenjang SD/MI, 12 guru jenjang SMP/MTs, dan 15 guru jenjang SMA/SMK/MA dari 39 sekolah di Kota Batu, Jawa Timur. Pelaksanaan kegiatan dilakukan selama 8 bulan dengan metode Forum Group Discussion (FGD), workshop, praktek langsung, sosialisasi, dan pelatihan. Pelatihan pengabdian masyarakat dilakukan menyeluruh, dari proses hingga keluaran, terutama keseriusan guru mengikuti kegiatan hingga keterampilan menerapkan model pembelajaran OIDDE. Hasil proses workshop dan pelatihan menunjukkan, bahwa kegiatan pengabdian terlaksana dengan baik, rata-rata kehadiran mencapai $85 \%$, dan sebanyak $100 \%$ guru menjadi Master Teacher model pembelajaran OIDDE, dan 
berhak memberikan tutor model pembelajaran OIDDE. Implikasi dari kegiatan pengabdian meliputi: tersosialisasinya model pembelajaran OIDDE, guru menjadi mudah melakukan peningkatan keaktifan belajar siswa, guru dapat melakukan pengukuran perilaku siswa secara verbal.

\section{PENDAHULUAN}

Membangun generasi emas bangsa Indonesia di tahun 2045 harus dimulai dengan membangun tiga keterampilan penting bagi siswa di abad 21 ini. Tiga keterampilan penting yang harus dikuasai Peserta Didik, sebagaimana dinyatakan Kemendikbud (2017) adalah 1) membangun kualitas karakter yang meliputi lima aspek, yaitu religiusitas, nasionalisme, kemandirian, gotong royong, dan integritas; 2) literasi dara, meliputi: literasi bahasa, literasi numerasi, literasi sains, literasi digital (teknologi) informasi dan komunikasi, literasi finansial, dan literasi budaya dan kewargaan; 3) kompetensi memecahkan masalah kompleks secara, berpikir kritis, kreativitas, komunikasi, dan kolaborasi.

Terkait dengan membangun kualitas karakter pada siswa, pemerintah telah menetapkan Peraturan Presiden (Perpres) Nomor 87 Tahun 2017 tentang Penguatan Pendidikan Karakter (PPK) yang tujuannya adalah: 1) membangun dan membekali Peserta Didik sebagai generasi emas Indonesia Tahun 2045 dengan jiwa Pancasila dan pendidikan karakter yang baik guna menghadapi dinamika perubahan di masa depan; 2) mengembangkan platform pendidikan nasional yang meletakkan pendidikan karakter sebagai jiwa utama dalam penyelenggaraan pendidikan bagi Peserta Didik dengan dukungan pelibatan publik yang dilakukan melalui pendidikan jalur formal, nonformal, dan informal dengan memperhatikan keberagaman budaya Indonesia; dan 3) merevitalisasi dan memperkuat potensi dan kompetensi pendidik, tenaga kependidikan, Peserta Didik, masyarakat, dan lingkungan keluarga dalam mengimplementasikan PPK.

Ditegaskan pula dalam Perpres Nomor 87 Tahun 2017 tentang PPK, bahwa pelaksanaan PPK pada satuan pendidikan jalur formal dilakukan secara terintegrasi melalui kegiatan intrakurikuler, kokurikuler, dan ekstrakurikuler. Kegiatan intrakurikuler dari penyelenggarnaan PPK adalah penguatan nilai-nilai karakter melalui penguatan materi pembelajaran, kegiatan kokurikuler penyelenggarnaan PPK dilaksanakan melalui pendalaman dan/atau pengayaan intrakurikuler, dan kegiatan ekstrakuriluer penyelenggaraan PPK melalui penguatan kegiatan perluasan potensi, bakat, minat, kemampuan, kepribadian, kerjasama, dan kemandirian siswa secara optimal.

Pentingnya pembelajaran berbasis karakter adalah untuk mengantisipasi meluasnya penyimpangan perilaku yang dilakukan siswa. Perilaku menyimpang yang marak dilakukan siswa dan telah melanda negeri ini adalah pelanggaran etika, seperti pergaulan bebas yang menyebabkan seks pranikah, penggunaan narkoba, minuman keras, perilaku tidak hormat pada orang lain, pornografi, pornoaksi, tawuran pelajar, dan berbagai tindak amoral lainnya (Lestari, Ika Ayu., Fibriana, A. I., \& Prameswari, 2014; Hudha, A. M., 2015; dan Oktriyanto, O. \& Alfiasari, 2019), dan tidak menutup kemungkingan 
terjadi pada pelajar di Kota Batu. Oleh sebab itu, upaya yang harus dilakukan oleh setiap sekolah membentengi para siswanya dengan pendidikan karakter melalui model pembelajaran yang tepat. Sebab menurut Aeni, K., Widhanarto, G. P., \& Astuti (2020); dan Sobri, M., Nursaptini, W. A., \& Sutisna, (2019) pembentukan karakter positif siswa saat ini dominan pada kegiatan budaya sekolah.

Penerapan karakter positif melalui budaya sekolah menjadi atmosfir di banyak sekolah, dan belum banyak melalui mata pelajaran. Berkaitan dengan pembelajaran di kelas Hudha, et al. $(2015,2018)$ menyatakan, bahwa banyak guru mengalami kesulitan dalam menerapkan pembelajaran bermuatan nilainilai karakter di kelas karena belum dapat memilih metode maupun model pembelajaran yang tepat. Hal inilah yang menyebabkan mengapa pendidikan karakter dominan pada budaya sekolah, dan nilai-nilai karakter yang diharapkan muncul melalui mata pelajaran hanya tertuang dalam Rencana Pelaksanaan Pembelajaran (RPP) saja dan sulit dimunculkan. Hal ini tentu tergambarkan pada berbagai jenjang sekolah-sekolah di kota Batu.

Pembelajaran berorientasi nilai-nilai karakter pada semua mata pelajaran belum menjadi wacana yang luas di kota Batu, sehingga para guru dalam mengajar mata pelajaran yang diajarkan masih konvensional atau lazimnya selama ini. Nilai-nilai karakter dibentuk melalui budaya sekolah, belum terintegrasi secara nyata dalam pembelajaran melalui mata pelajaran. Kondisi demikian tentu akan lebih baik jika muatan nilai-nilai karakter terintegrasi nyata dalam setiap mata pelajaran, sehingga nilai-nilai karakter selain dibentuk melalui budaya sekolah juga dibentuk dan ditumbuhkan melalui mata pelajaran di kelas.

Menyikapi kesulitan para guru di kota Batu dalam memilih metode atau model pembelajaran yang tepat untuk mengimplementasikan pembelajaran berbasis karakter melalui pembelajaran mata pelajaran, perlu dilakukan upaya sosialisasi model pembelajaran yang layak dan tepat. Salah satu alternatif pemilihan model pembelajaran yang tepat adalah model pembelajaran OIDDE. Sebagaimana dinyatakan Hudha, et al. $(2016,2018)$ sebagai akronim dari Orientation, Identify, Discussion, Decision, Engage in Behavior. Sosialisasi model pembelajaran OIDDE sangat penting untuk meningkatkan pengetahuan dan keterampilan guru dalam mengajar, sehingga para guru mendapatkan penguatan (reinforcement) dalam meningkatkan pelaksanaan pembelajaran bermuatan nilai karakter melalui pembelajaran di kelas. Apalagi menurut Nurcahya, A., \& Hadijah, H. S., (2020) dampak guru mampu memberikan penguatan (reinforcement) dalam pembelajaran berpengaruh terhadap motivasi belajar siswa.

Berdasarkan fakta dan kondisi yang telah dipaparkan, perlu dilaksanakan pendampingan penerapan model pembelajaran yang layak dan tepat kepada para guru di kota Batu, agar mampu melaksanakan pembelajaran yang berorientasi nilai-nilai karakter. Upaya yang dilakukan adalah memberikan pendampingan penerapan model pembelajaran OIDDE sebagai langkah strategis meningkatkan keterampilan para guru dalam melaksanakan pembelajaran berorientasi nilai-nilai karakter. 
Sebagaimana menurut Hudha et al. $(2016,2018)$ bahwa model pembelajaran OIDDE sangat sangat efektif untuk meningkatkan pengetahuan etika kehidupan (bioetika), kemampuan pengambilan keputusan etik, dan sikap etis, maka model ini penting diterapkan secara luas. Model pembelajaran OIDDE merupakan model pembelajaran yang dikembangkan untuk diterapkan dalam memecahkan berbagai problema dilematis yang dapat menghasilkan perilau etis pada Peserta Didik. Perilaku etis dimaksud menurut Hudha et al. $(2016,2018)$ antara lain sikap etis, dan kemampuan mengambil keputusan etis. Adapun tahapan-tahapan (sintaks) model pembelajaran OIDDE yang sekaligus menjadi akronimnya adalah orientation, identify, disccussion, decisions, dan engage in behavior (Hudha et al., 2016, 2018a, 2018b).

Model pembelajaran OIDDE telah terbukti efektif dalam pengembangan dan peningkatan nilai-nilai karakter Peserta Didik, yaitu bersikap dan berperilaku etis, kemampuan berpikir kritis, kemampuan berpikir metakognitif, maupun kemampuan mengambil keputusan etis. Penelitian Fariati, E., Hudha, A. M., \& Husamah (2017) menunjukkan, bahwa model pembelajaran OIDDE mampu menumbuhkan pemahaman Peserta Didik terhadap pertimbangan etis yang berhubungan dengan seks pranikah. Kemampuan Peserta Didik dalam melakukan identifikasi berbagai faktor yang berkaitan dengan seks pranikah mengindikasikan memiliki pengetahuan cukup baik atau tinggi, dan berarti sangat positif bagi Peserta Didik. Hasil penelitian Pantiwati, Y., Husamah, H., \& Hudha (2016) juga menunjukkan, bahwa penerapan model pembelajaran OIDDE pada kegiatan Studi Lapang Terintegrasi di Luar Negeri telah membantu Peserta Didik mampu mengidentifikasi masalah etis dan pengambilan keputusan etis terkait masalah etika di lingkungannya. Hasil penelitian Setyawan (2017) menyatakan, bahwa penerapan model pembelajaran OIDDE meningkatkan kemampuan berpikir kritis dan hasil belajar mahasiswa. Selanjutnya Hudha et al. (2018) menunjukkan, bahwa implementasi model pembelajaran OIDDE telah meningkatkan pengetahuan bioetika, kemampuan mengambil keputusan etis, dan sikap etis pada mahasiswa calon guru biologi.

Oleh karena itu, solusi yang diperlukan untuk menjawab pentingnya pembelajaran berbasis karakter dapat dilaksanakan oleh para guru pada jenjang pendidikan dasar dan menengah di kota Batu, model pembelajaran OIDDE menjadi pilihan utama. Berdasasrkan hal tersebut, maka penulisan artikel ini bertujuan mendeskripsikan kegiatan pendampingan penerapan model pembelajaran OIDDE untuk meningkatkan keterampilan pembelajaran berbasis karakter pada guru di Kota Batu.

\section{METODE PELAKSANAAN}

Model pengabdian yang digunakan adalah kerjasama kemitraan, workshop, dan pelatihan dengan subjek atau khalayak sasaran para guru di Kota Batu yaitu 12 guru jenjang SD/MI, 12 guru jenjang SMP/MTs, dan 15 guru jenjang SMA/SMK/MA dari 39 sekolah di Kota Batu, Jawa Timur. Kegiatan pengabdian dilaksanakan pada jenjang pendidikan dasar (SD dan/atau MI) dan pendidikan menengah (SMP dan SMA/SMK/MA) yang ada di Kota Batu selama 8 bulan. Alat dan bahan yang digunakan adalah perangkat peralatan 
presentasi, materi, dan laptop untuk mencatat kegiatan dan kamera untuk pendokumentasian. Dalam mengatasi permasalahan yang dihadapi oleh sekolah mitra, prosedur kerja dan metode pelaksanaan pengabdian yang telah didiskusikan dan disepakati bersama dengan kedua sekolah mitra adalah sebagai berikut:

1. Focus Group Discussion (FGD): Kegiatan FGD ini dilaksanakan tim pengabdi untuk merancang kegiatan yang akan dilaksanakan dalam kurun waktu 8 bulan. Pada tahap ini disepakati pembagian tugas (Job Description) pada masing-masing pihak, yaitu tim pengabdi, dan guru yang ditunjuk oleh sekolah.

2. Pelatihan/Workshop dan Pendampingan: Kegiatan ini berupa mengenalkan model pembelajaran OIDDE dan pengimplementasiannya dalam pembelajaran di kelas.

3. Diseminasi: Berbagai best practices yang diperoleh Master Teacher dan tim pengabdian akan didesiminasikan kepada guru-guru lain di sekolah masing-masing Master Teacher di Kota Batu. Berdasarkan uraian di atas maka metode pelaksanaan yang mengacu kepada analisis situasi program-program yang disepakati bersama dengan mitra adalah sebagaimana diuraikan pada Tabel 1.

Tabel 1. Prosedur Kerja dan Metode Pelaksanaan Pengabdian

\begin{tabular}{|c|c|c|}
\hline No & Langkah Kegiatan Pengabdian & Metode \\
\hline 1. & $\begin{array}{l}\text { Focus Group Discussion dan Penyamaan persepsi dengan } \\
\text { pihak Dinas Pendidikan dan Kebidayaan Kota Batu, } \\
\text { Kementerian Agama Kota Batu, dan Komisi Pengkaderan Ulama } \\
\text { dan Pendidikan MUI Kota Batu. }\end{array}$ & Diskusi \\
\hline \multirow[t]{5}{*}{2.} & Workshop dan Pelatihan Model Pembelajaran OIDDE & \\
\hline & a. Sesi 1: Penyampaian materi pengantar. & Ceramah interaktif \\
\hline & $\begin{array}{l}\text { b. Sesi 2: Latar belakang pelaksanaan kegiatan dan best } \\
\text { practices implementasi pembelajaran OIDDE selama ini. }\end{array}$ & Ceramah interaktif \\
\hline & c. Sesi 3: Diskusi sintaks model pembelajaran OIDDE. & Diskusi \\
\hline & $\begin{array}{l}\text { d. Sesi 4: Pendampingan penerapan model pembelajaran } \\
\text { OIDDE }\end{array}$ & Diskusi dan pemodelan. \\
\hline 3. & Monitoring dan evaluasi & Diskusi \\
\hline 4. & Publikasi dan Pelaporan Akhir & $\begin{array}{l}\text { Praktek langsung dan } \\
\text { diskusi }\end{array}$ \\
\hline
\end{tabular}

Lembaga pendidikan yang menjadi mitra dalam kegiatan pegabdian ini adalah 38 Sekolah di Kota Batu, merupakan lembaga pendidikan di bawah naungan Dinas Pendidikan dan Kebudayaan Kota Batu dan Kementerian Agama Kota Batu. Kerjasama kelembagaan yang terjalin selama ini, baik antara Fakultas Keguruan dan IImu Pendidikan Universitas Muhammadiyah Malang dengan lembaga-lembaga dimaksud atau Tim secara pribadi atau mandiri memudahkan kemitraan dan pola komunikasi, berlandaskan semangat bersama-sama memajukan pendidikan.

Teknik pengumpulan data dilakukan dengan melakukan observasi melalui pengisian data dalam google form oleh para guru terpilih di masingmasing sekolah, melakukan diskusi, dan sosialisasi serta workshop yang didokumentasikan melalui catatan-catatan, pengarsipan sampel produk 
kegiatan yang dihasilkan, dan dokumentasi kamera. Dalam perjalanan pengabdian Tim pengabdi melakukan workshop yang bekerjasama dengan Dinas Pendidikan dan Kebudayaan Kota Batu, Kementerian Agama Kota Batu yang selanjutnya mengembangkan kerjasama dengan Majelis Ulama Indonesia Kota Batu untuk menggelar workshop model pembelajaran OIDDE. Data-data yang diperoleh selanjutnya dianalisis secara deskriptif kualitatif yang didukung dengan data kuantitatif. Pengabdian dilakukan secara holistik dan menyeluruh, mulai proses hingga output, khususnya terkait keseriusan atau antusiasme para guru mengikuti kegiatan peningkatan pengetahuan tentang model dan keterampilan mengimplementasikan model pembelajaran OIDDE melalui pelatihan. Keberhasilan atas proses kegiatan dilihat dengan menghitung rerata keaktifan kehadiran para guru, dimana dianggap berhasil bila $\geq 75 \%$ guru hadir dengan antusias dan semangat serta serius mengikuti kegiatan, aktif bertanya, aktif terlibat dalam pengenalan dan pengimplementasian model pembelajaran OIDDE (teknik non-tes). Adapun keberhasilan output dilihat dari kemampuan para guru dalam mengimplementasikan model pembelajaran OIDDE di kelas model.

\section{HASIL DAN PEMBAHASAN}

Kegiatan pengabdian telah dirancang dan dilaksanakan selama 8 bulan melalui koordinasi dengan Dinas Pendidikan dan Kebudayaan Kota Batu, Kementerian Agama Kota Batu, dan Komisi Pengkaderan Ulama dan Pendidikan MUI Kota Batu. Adapun kegiatan-kegiatan yang telah dilaksanakan tersebut di uraikan sebagai berikut:

\section{Penyamaan Persepsi dengan Dinas Pendidikan dan Kebudayaan Kota Batu serta Kementerian Agama Kota Batu}

Kegiatan tersebut dilaksanakan secara simultan diantara kegiatan yang paling konsisten dilaksanakan pada 15 dan 16 Oktober 2020 serta pada tanggal 22 dan 23 November 2020. Dalam pernyamaan persepsi Tim telah menyampaikan secara terperinci gambaran kegiatan yang akan dilaksanakan, bahwa berdasarkan kesepakatan yang telah dinyatakan sebelumnya, maka akan dilaksanakan kegiatan pendampingan pada guru yang menjadi utusan dari setiap sekolah sampel. Hasil kegiatan ini dilaksanakan di bawah koordinasi Dinas Pendidikan dan Kebudayaan Kota Batu, dan Kementerian Agama Islam Kota Batu, serta dukungan penuh Komisi Pengkaderan Ulama dan Pendidikan Majelis Ulama Indonesia Kota Batu untuk kesuksesan kegiatan, karena tema yang di angkat sangat tepat untuk kondisi riil di sekolah. Bahkan, merencanakan untuk dilakukan kegiatan bergelombang di masa mendatang jika memungkinkan, agar banyak guru di Kota Batu menjadi master teacher dari konsep yang diajukan Tim, yaitu penerapan pembelajaran berbasis karakter melalui model pembelajaran OIDDE.

\section{Workshop Pembelajaran OIDDE}

Sebelum pelaksanaan kegiatan workshop dilakukan pertemuan Pra-Workshop dengan Dinas Pendidikan dan Kebudayaan Kota Batu serta audiensi dengan Kementerian Agama Kota Batu yang dilaksanakan pada 
1 Desember 2020. Hasil dari pertemuan ini mendorong Majelis Ulama Indonesia (MUI) Kota Batu, melalui Komisi Pengkaderan Ulama dan Pendidikan merasa berkepentingan untuk terlibat dalam kegiatan ini, sehingga Workshop akan diwadahi oleh Komisi Pengkaderan Ulama dan Pendidikan MUI Kota Batu yang secara kebetulan merencanakan kegiatan pendidikan di sekolah dengan tema Goes to School. Berdasarkan pertemuan tanggal 1 Desember 2020 akhirnya disepakati, bahwa workshop dilaksanakan pada tanggal 21 Desember 2020.

Kegiatan workshop pembelajaran OIDDE dilaksanakan pada 21 Desember 2020 di Hall Hotel Ciptaning Ati Kota Batu, mulai pukul 07.30 sampai pukul $15.00 \mathrm{WIB}$, diikuti sebanyak 38 orang peserta dari 38 sekolah sebagaimana disajikan pada Tabel 2 .

Tabel 2. Peserta Pengabdian

\begin{tabular}{clcc}
\hline No. & \multicolumn{1}{c}{ Peserta } & Jumlah (Orang) & Keterangan \\
\hline 1. & Guru SMA/SMK/MA & 14 & Aktif mengikuti kegiatan secara penuh \\
$(100 \%)$ \\
2. & Guru SMP/MTs & 12 & $\begin{array}{c}\text { Aktif mengikuti kegiatan secara penuh } \\
(100 \%)\end{array}$ \\
3. & Guru SD/MI & 12 & Aktif mengikuti kegiatan secara penuh \\
& & & $(100 \%)$ \\
4. & Tim Pengabdi & 3 & Aktif \\
5. & Tenaga Pembantu & 4 & Aktif \\
\hline
\end{tabular}

Pelaksanaan kegiatan ini diawali dengan Sesi 1 yaitu penyampaian materi pengantar. Pada tahap ini dilaksanakan penyampaian sambutan atau pengantar dari MUI Kota Batu dan Dinas Pendidikan dan Kebudyaan Kota Batu. Pihak MUI Kota Batu serta Dinas Pendidikan dan Kebudayaan Kota Batu sangat mendukung dan mengapresiasi pelaksanaan kegiatan ini, terutama karena Tim pelaksanan pengabdian telah memilih Lembaga mereka sebagai mitra. Kegiatan ini mendukung upaya Dinas Pendidikan dan Kebudayaan Kota Batu untuk meningkatkan kualitas pembelajaran di setiap satuan pendidikan di Kota Batu. Upaya-upaya yang mendorong peningkatan kualitas para guru di setiap satuan pendidikan di Kota Batu terkait model pembelajaran terkini, kontekstual, dan mendorong terlaksananya active learning, sehingga mendukung terlaksananya pembelajaran berpusat pada siswa (Student Centered Learning).

Sesi 2 adalah presentasi tentang latar belakang pelaksanaan kegiatan dan best practices implementasi pembelajaran OIDDE yang dilakukan selama ini. Tim pengabdi menyampaikan berbagai kondisi yang menjadi latar belakang mengapa kegiatan pengabdian ini perlu dilakukan, khususnya terkait dengan problema implementasi nilai karakter di masyarakat secara umum dan khususnya di sekolah oleh guru dalam pelaksanaan pembelajaran. Juga tuntutan untuk berkolaborasi dengan sekolah atau madrasah sebagai tanggung jawab tridharma perguruan tinggi, serta tren hasil penelitian dan publikasi yang telah dilaksanakan tim selama sepuluh tahun terakhir. 
Pada sesi 2 hasil-hasil penelitian serta publikasi berbasis model pembelajaran OIDDE juga dipaparkan sebagai bukti ilmiah penerapan model selama ini. Tim pengabdi juga menegaskan, bahwa model pembelajaran OIDDE telah diterapkan di puluhan sekolah di Malang Raya, baik level SMP, SMA, ataupun juga SMK. Bahkan telah menjadi salah satu topik yang memenangkan hibah penelitian BKKBN tingkat Provisi Jawa Timur dan mewakili Provinsi Jawa Timur untuk seleksi di tingkat Nasional yang akhirnya lolos di tingkat nasional sehingga berhak mendapatkan dana hibah dari BKKBN Pusat di Jakarta. Demikian juga model pembelajaran OIDDE telah menjadi solusi untuk mengatasi permasalahan pembelajaran di berbagai jenjang sekolah dan menjadikannya judul penelitian untuk skripsi dan tesis.

Beberapa penelitian skripsi mahasiswa Strata-1 di Program Studi Pendidikan Biologi Fakultas Keguruan dan IImu Pendidikan Universitas Muhammadiyah Malang maupun mahasiswa Strata-2 Pascasarjana Universitas Pendidikan Indonesia (UPI) Bandung menjadikan model pembelajaran OIDDE untuk penelitiannya. Demikian juga model pembelajaran OIDDE telah mengantarkan guru SMKN 6 Kota Malang sukses mempresentasikan penelitiannya pada pertemuan ilmiah di luar negeri (Malaysia). Model pembelajaran OIDDE juga banyak dipakai dalam pembelajaran oleh para dosen, khususnya di lingkungan Program Studi Pendidikan Biologi, Fakultas Keguruan dan IImu Pendidikan Universitas Muhammadiyah Malang serta menjadi topik penelitian skripsi dan tesis mahasiswa, baik di Prodi Pendidikan Biologi.

Hasil dari kegiatan sesi 2 ini adalah tumbuhnya penyamaan pemahaman terkait tema pengabdian, alasan dan landasan empiris serta filosofis mengapa perlu kegiatan pengabdian, dan alasan mengapa tema pengabdian pendampingan implementasi model pembelajaran OIDDE untuk meningkatkan pembelajaran berbasis karakter bagi guru di Kota Batu sangat perlu untuk dilaksanakan. Semua guru menyampaikan kesamaan pikiran mereka terkait permasalahan tersebut, dan memang menganggap bahwa problema nilai karakter mendesak untuk direspon. Mereka sebagai guru memiliki peran strategis untuk terlibat menyelesaikan atau mengatasi problema karakter, terlepas apapun mata pelajaran yang diampu.

Sesi 3 merupakan presentasi sintaks model pembelajaran OIDDE dan contoh implementasinya (modelling). Tim mempresentasikan latar belakang pengembangan model OIDDE dan menjelaskan tahapantahapan pembelajaran (sintaks) model pembelajaran OIDDE secara terperinci. Pada tahap ini disampaikan pula bagaimana mengimplementasi model ini dalam mata pelajaran. Ketua pelaksana menjelaskan satu persatu pelaksanaan sintaks dalam pembelajaran dengan mengambil salah satu mata pelajaran di sekolah. Oleh karena para guru yang dikirim dari setiap sekolah mayoritas guru pendidikan agama, maka ketua pelaksana mengambil mata pelajaran agama Islam sebagai contoh implementasi sintaks model pembelajaran OIDDE. 
Sesi 4 merupakan penerapan pendampingan model pembelajaran OIDDE secara nyata. Pada tahap ini ketua pelaksana berperan sebagai guru dan para peserta berperan sebagai siswa. Mengingat peserta dominan dari guru Pendidikan Agama Islam, dan untuk menempatkan penerapan model pembelajaran OIDDE lebih implementatif, maka pemodelan yang dilakukan ketua pelaksanan adalah menerapkan materi pelajaran agama SMA/SMK Kelas XI Bab 1-2, yaitu setiap sintaks model pembelajaran OIDDE pada mata pelajaran agama di SMA/SMK kelas XI Bab 1-2 yaitu menelaah QS al-Maidah/5:48. Pada sesi 4 ini seluruh peserta melaksanakan pembelajaran OIDDE, sehingga merasakan bagaimana diperlakukan sebagai siswa dan menjadikannya lebih aktif dalam belajar, karena pembelajaran berpusat pada siswa (Student Centered Learning). Sebagaimana Jandrić (2020), Harsono (2008), Antika, (2014), Hoidn (2016), dan Jacobs and Power (2016) menyatakan, bahwa dalam SCL menempatkan mahasiswa leluasa mengembangkan segenap potensinya baik cipta, karsa dan rasa, serta mengeksplorasi bidang atau ilmu yang diminatinya, membangun pengetahuan serta kemudian mencapai kompetensinya melalu proses pembelajaran aktif, interaktif, kolaboratif, kooperatif, kontekstual, dan mandiri. Setelah pemodelan dilakukan sesi pemantapan dan tanya jawab. Para guru bertanya berbagai hal, khususnya strategi mengatur waktu, cara memastikan penerapan sintaks dengan tepat, penilaian siswa, dan mengukur perkembangan dan perubahan aspek perilaku. Pada Sesi 4 ini para guru tampak sangat antusias mengikuti modeling yang dilakukan dan aktif bertanya atau berdiskusi.

Berdasarkan Tabel 4, dapat dinyatakan, bahwa pemodelan yang dilaksanakan merupakan hal baik dan positif dalam upaya untuk meningkatkan kualitas pembelajaran yang harus dilakukan guru. Oleh karena itu, dalam praktek selanjutnya, hal-hal berikut ini sangat perlu diperhatikan, yaitu:

Tabel 3. Komentar Para Guru Terhadap Hasil Pendampingan Model Pembelajaran OIDDE

\section{No. Repon Guru Terhadap Model Pembelajaran OIDDE}

1. Mendapatkan kesempatan berharga dapat mengenal model pembelajaran baru yang cocok untuk digunakan mengajar siswa.

2. Mendorong rasa ingin mencoba dalam pembelajaran nyata di kelas luring.

3. Memberikan peningkatan pengetahuan serta keterampilan baru dalam mengajar dengan model pembelajaran yang mendorong peningkatan nilai-nilai karakter melalui mata pelajaran di kelas.

4. Pembelajran lebih menyenangkan dan lebih aktif.

5. Peserta didik (siswa) benar-benar menjadi aktif, belajarnya lebih menyenangkan, kreatif, dan produktif.

6. Peran serta masing-masing peserta didik (siswa) dalam belajar lebih nyata dan lebih dihargai.

7. Pembelajaran harus memperhatikan waktu, karena di tahap diskusi bisa menghabiskan banyak waktu jika tidak dibatasi.

8. Mencari masalah karakter dalam bidang agama yang dapat ditunjukkan oleh perilaku verbal siswa setelah pembelajaran di kelas merupakan tantangan menarik bagi guru.

9. Jika dalam bidang pembelajaran agama model pembelajaran OIDDE dapat diterapkan dengan menarik, pasti dalam mata pelajaran yang lainpun model pembelajaran OIDDE dapat diterapkan dengan baik. 
Pembelajaran berbasis karakter merupakan hal yang sangat penting, mulai dari jenjang pra-sekolah, pendidikan dasar, pendidikan menengah, hingga perguruan tinggi (Sutjipto, 2011; Susanti, 2013). Pembelajaran berbasis karakter tidak saja harus dilakukan melalui kegiatan budaya sekolah maupun kegiatan ekstrakurikuler, namun kegiatan kokurikuler dan intra kurikuler harus menjadi ruang untuk melaksanakan pembelajaran karakter. Implementasi pendidikan karakter (IPK) harus diubah strateginya tidak dengan menambah mata pelajaran baru tentang pendidikan karakter melainkan melakukan penajaman kurikulum karakter dan nilai-nilai luhur yang ditransformasikan kepada siswa (Wiyono, 2012). Tentunya, penajaman kurikulum karakter diwujudkan melalui pelaksanaan pembelajaran mata pelajaran apapun di kelas dengan berbasis karakter, sehingga hasil belajar yang diharapkan selain peningkatan kognitif, juga afektif, dan psikomotor. Peningkatan kognitif dalam bentuk kompetensi pengetahuan siswa yang semakin bertambah dan hasil belajar yang baik, peningkatan afektif ditunjukkan dengan perubahan sikap dan perilaku yang semakin baik, dan peningkatan psikomotor di tunjukkan dengan tindakan nyata perilaku baik siswa. Dengan demikian, maka pengembangan sikap, spritual, sosial, rasa ingin tahu, kreativitas, kerjasama, dengan kemampuan intelektual dan psikomotorik membutuhkan model pembelajaran yang inovatif (Puspitasari, Nur Aini \& Hidayatullah, 2020), dan salah satu jawabannya adalah model pembelajaran OIDDE.

Menyikapi permasalahan demikian, hal penting yang dapat dilakukan guru adalah perlunya contoh dan teladan bagi siswa, mengkoreksi kekeliruan siswa dengan melakukan pembiasaan yang mengintegrasikan dalam pembelajaran yang tepat (Wuryandari, Wuri., Fathurrohman, F., \& Ambarwati, 2016). Guru akan berkontribusi pada karakter siswa jika mereka menjalankan tugas berdasar kemampuan sendiri untuk melakukan, serta merenungkan pekerjaan yang dilandasi rasa hormat terhadap diri mereka sendiri, serta mempraktekkan apa yang mereka ajarkan (Opazo, H., Aramburuzabala, P. \& García-Peinado, 2014). Pendampingan guru mengembangkan pembelajaran berbasis karakter sangat penting dilakukan, karena menurut (Husamah, H., Hudha, A. M., \& Pantiwati, Y., 2018) guru merupakan aktor utama dalam menanamkan karakter maupun nilai-nilai etis.

Kegiatan pengabdian ini telah memberikan salah satu alternatif pembelajaran berbasis karakter yang dapat diterapkan oleh guru dengan mata pelajaran apapun melalui Model Pembelajaran OIDDE. Hasil positif dari pengabdian yang telah dilaksanakan ini sejalan dengan kegiatan pengabdian yang telah dilaksanakan oleh Husamah et al. (2018) sebelumnya, yang hasilnya secara positif semua guru menyatakan, bahwa model pembelajaran OIDDE mampu memberikan pengatahuan baru terkait model pembelajaran yang berhubungan dengan karakter, moral, dan etika. Oleh karena itu, apabila model pembelajaran OIDDE ini secara konsisten diterapkan, maka aspek karakter yang dibangun melalu pembelajaran mata pelajaran di kelas sangat dimungkinkan akan tercapai dengan baik. 
Implikasi dari kegiatan pengabdian ini meliputi: tersosialisasinya model pembelajaran OIDDE, guru menjadi mudah melakukan peningkatan keaktifan belajar siswa, guru dapat melakukan pengukuran perilaku siswa secara verbal, sehingga karakter siswa terbentuk melalui model pembelajaran OIDDE.

\section{KESIMPULAN}

Kegiatan pengabdian telah dilaksanakan sesuai dengan rencana yang ditetapkan dengan kegiatan penyamaan persepsi dengan pihak Dinas Pendidikan dan Kebudayaan Kota Batu, Kementerian Agama Kota Batu, dan Komisi Pengkaderan Ulama dan Pendidikan MUI Kota Batu serta Workshop Pendidikan Model Pembelajaran OIDDE. Workshop dan pelatihan terdiri atas empat sesi, yaitu a) penyampaian materi pengantar; b) latar belakang pelaksanaan kegiatan dan best practices implementasi model pembelajaran OIDDE selama ini; c) diskusi sintaks model pembelajaran OIDDE; d) pendampingan penerapan model pembelajaran OIDDE. Implikasi nyata dari kegiatan pengabdian ini anara lain: tersosialisasinya model pembelajaran OIDDE, guru menjadi mudah melakukan peningkatan keaktifan belajar siswa, guru dapat melakukan pengukuran perilaku siswa secara verbal, sehingga karakter siswa terbentuk melalui model pembelajaran OIDDE.

Saran untuk kegiatan selanjutnya adalah diharapkan peserta pengabdian menjadi master teacher model pembelajaran OIDDE di masingmasing sekolahnya, sehingga model pembelajarn OIDDE dapat terimplementasi secara luas. Disarankan kepada pembaca untuk mengenal model pembelajaran OIDDE dengan lebih baik, melalui berbagai sumber berkaitan model pembelajaran OIDDE, agar menjadi sumber belajar yang memudahkanuntuk memahami implementasi model dalam pembelajaran berorientasi pembentukan karakter. Harapannya para pembaca, khususnya para guru dapat memanfaatkam model pembelajaran OIDDE guna pembentukan team teaching untuk meningkatkan profesionalisme guru dalam penguasaan berbagai model pembelajaran yang ada lainnya.

\section{UCAPAN TERIMA KASIH}

Tim pengabdi mengucapkan terima kasih kepada Dekan FKIP Universitas Muhammadiyah Malang (Dr. Poncojari Wahyono, M.Kes) dan Ketua Tim Block Grant FKIP Universitas Muhammadiyah Malang Tahun 2020 (Dr. Rr. Eko Susetyorini, M.Si.) yang telah memberikan dana untuk pelaksanaan kegiatan pengabdian kepada masyarakat ini. Ucapan terima kasih juga Tim pengabdi sampaikan kepada Kepala Dinas Pendidikan dan Kebudayaan Kota Batu, Kepala Kementerian Agama Islam Kota Batu, dan Ketua Umum MUI Kota Batu yang kesemuanya telah memberikan dukungan pelaksanaan kegiatan pengabdian ini.

\section{DAFTAR RUJUKAN}

Aeni, K., Widhanarto, G. P., \& Astuti, T. (2020). Strengthening character education in elementary schools: Learning technology in school culture. 
International Journal of Science \& Technology Research, 9(2), 898-902. https://www.ijstr.org/final-print/feb2020/The-Lake-As-An-Urban-

Ecological-Balance-In-Depok-City.pdf

Antika, R. R. (2014). Proses pembelajaran berbasis Student Centered Learning (Studi deskriptif di Sekolah Menengah Pertama Islam Baitul 'Izzah, Nganjuk). BioKultur, 3(1), 251-263.

Fariati, E., Hudha, A. M., \& Husamah, H. (2017). Pengetahuan dan keputusan etis siswa SMK Negeri 6 Malang terhadap permasalahan perilaku seks pra-nikah melalui model pembelajaran OIDDE.

Harsono, H. (2008). Student-centered learning di Perguruan Tinggi. Jurnal Pendidikan Kedokteran Dan Profesi Kesehatan Indonesia, 3(1), 4-8.

Hoidn, S. (2016). The pedagogical concept of Student-Centred Learning in the context of European Higher Education reforms. European Scientific Journal, 12(28), 439-458. https://doi.org/DOI: https://doi.org/10.19044/esj.2016.v12n28p439

Hudha, A., H., Amin, M., Sumitro,S., B. \& Akbar, S. (2018). The effectiveness of OIDDE learning model in the improvement of bioethics knowledge, ethical decision, and ethical attitude of biology preservice teachers. Journal of Baltic Science Education, 17(6), 960-971. https://doi.org/10.33225/jbse/18.17.960

Hudha, A., H. (2015). Kajian Pengetahuan Bioetika dan Kemampuan Pengambilan Keputusan Etis Mahasiswa Calon Guru Biologi. Seminar Nasional Pendidikan Biologi, 530-538.

Hudha, A. M. (2018). Pengembangan Model Pembelajaran OIDDE (Orientation, Identify, Discussion, Decision, and Engage in Behavior) dan Pengaruhnya Terhadap Peningkatan Pengetahuan Bioetika, Keputusan Etik, dan Sikap Etis Mahasiswa Program Studi Pendidikan Biologi FKIP UMM. In DISERTASI dan TESIS Program Pascasarjana UM. http://karya-ilmiah.um.ac.id/index.php/disertasi/article/view/76210

Hudha, A. M., Amin, M., Bambang, S., \& Akbar, S. (2016). Study of Instructional Models and Syntax As An Effort for Developing OIDDE Instructional Model. Jurnal Pendidikan Biologi Indonesia, 2(2), 109-124. https://doi.org/10.22219/jpbi.v2i2.3448

Husamah, Hudha, A. M., \& Pantiwati, Y. (2018). Pendampingan guru SMPN 8 Kota Malang dalam mengembangkan perilaku etis siswa berbasis model pembelajaran OIDDE. International Journal of Community Service Learning., 2(2), 41-50. https://doi.org/10.23887/ijcsl.v2i2.14185

Jacobs, George., Power, M. A. (2016). Student Centered Learning -an approach to fostering democracy in schools. Beyond Worda, 4(2), 7987. https://doi.org/DOI: https://doi.org/10.33508/bw.v4i2.940

Jandrić, P. (2020). Postdigital research in the time of Covid-19. Postdigital Science and Education, 2(2), 233-238. https://doi.org/10.1007/s42438020-00113-8

Kemendikbud. (2017). Pendidikan karakter dorong tumbuhnya kompetensi siswa adad 21.

Lestari, Ika Ayu., Fibriana, A. I., \& Prameswari, G. N. (2014). Faktor-faktor yang 
berhubungan dengan perilaku seks pranikah pada mahasiswa UNNES. Unnes Journal of Public Health, 3(2), 27-38.

Nurcahya, A., \& Hadijah, H. S. (2020). Pemberian penguatan (reinforcement) dan kreatifitas mengajar guru sebagai determinan motivasi belajar siswa. Jurnal Manajemen Pendidikan Perkantoran, 5(1), 83-96. https://doi.org/DOI:10.17509/jpm.v4i2.18008

Oktriyanto, o. and Alfiasari, A. (2019). Dating and premarital sexual inisiation on adolescence in Indonesia. Kemas Jurnal Kesehatan Masyarakat, 15(1), 98-108. https://doi.org/DOI:10.15294/kemas.v15i1.17270

Opazo, H., Aramburuzabala, P., \&, \& García-Peinado, R. (2014). Servicelearning methodology as a tool of ethical development: Reflections from the university experience. AISHE-J - The All Ireland Journal of Teaching and Learning in Higher Education, 6(1), 1531-15326.

Pantiwati, Y., Husamah, H., \& Hudha, A. M. (2016). Pembelajaran OIDDE melalui studi lapang terintegrasi luar negeri (SLT-LN) untuk mengembangkan kemampuan pengambilan keputusan etis calon guru bioogi.

Puspitasari, Nur Aini \& Hidayatullah, S. (2020). Peningkatan wawasan penerapan model pembelajaran berorientasi HOTS (Higher Order Thinking Skill) bagi guru MTs dan MA. JIPEMAS, 3(2), 128-135. https://doi.org/DOI: http://dx.doi.org/10.33474/jipemas.v3i2.6131

Setyawan, D. (2017). Penerapan model pembelajaran oidde pada matakuliah zoologi vertebrata untuk meningkatkan kemampuan berfikir kritis dan hasil belajar mahasiswa pendidikan biologi Universitas Muhammadiyah Malang.

Sobri, M., Nursaptini, W. A., \& Sutisna, D. (2019). Pembentukan karakter disiplin siswa melalui kultur sekolah. Harmoni Sosial: Jurnal Pendidikan IPS, 6(1),

$61-71$.

https://doi.org/DOI:http//dx.doi.prg/10.21831/hsjpi.v611.26912.

Susanti, R. (2013). Penerapan pendidikan karakter di kalangan mahasiswa. Jurnal Al-Ta'lim, 20(3), 480-487. https://doi.org/DOI: 10.15548/jt.v20i3.46

Sutjipto, S. (2011). Rintisan pengembangan pendidikan karakter di satuan pendidikan. Jurnal Pendidikan Dan Kebudayaan, 17(501-524).

Wiyono, H. (2012). Pendidikan karakter dalam bingkai pembelajaran di sekolah. Jurnal IImiah CIVIS, 2(2), 1-18.

Wuryandari, Wuri., Fathurrohman, F., \& Ambarwati, U. (2016). Implementasi pendidikan karakter kemandirian di Muhammadiyah boarding school. Jurnal Cakrawala Pendidikan, 35(2), 208-216. https://doi.org/DOI: https://doi.org/10.21831/cp.v15i2.9882 